\title{
Entre a praça e a escola: analisando processos de apropriação espacial através de uma abordagem complexa
}

Felipe Silveira de Souza*

\begin{abstract}
Resumo: Este ensaio trata dos processos de apropriação espacial do espaço público em comparação com o espaço escolar. Estes processos de apropriação espacial são vistos através dos conceitos de território e territorialidade, buscando, desse modo, compreender a forma como os grupos sociais - tribos urbanas - usam o espaço. Através da teoria da complexidade de Edgar Morin, buscamos estabelecer as similaridades e as diferenças entre os processos de apropriação espacial no espaço escolar e no espaço público. O entendimento dos processos de apropriação espacial na escola é visto como fundamental para a efetivação de uma ação pedagógica escolar mais condizente com a realidade social.

Palavras-chave: Apropriação espacial, Espaço escolar, Espaço público, Teoria da complexidade.
\end{abstract}

\begin{abstract}
This essay discusses the process of space appropriation of public space in comparison to the school's space. These processes of appropriation of space are seen through the concepts of territory and territoriality, seeking thereby to understand how social groups - urban tribes - use the space. Through the complexity theory of Edgar Morin, I sought to establish the similarities
\end{abstract}

\footnotetext{
Professor do Instituto Federal de Santa Catarina - Campus São José. Licenciado e Mestre em Geografia pela Universidade Federal do Rio Grande do Sul. Doutorando do Programa de Pós-Graduação em Geografia da Universidade Federal de Santa Catarina. E-mail: felipesouza@ifsc.edu.br
} 
and differences between the processes of appropriation of space in school and in public space. Understanding the spatial appropriation process in school is seen as crucial for the effectiveness of a school pedagogical action more in line with social reality.

Keywords: Space appropriation, School's space, Public space, Complexity theory.

Há algum tempo temos observado processos ocorrentes nos espaços públicos das grandes metrópoles. Em nossos trabalhos sobre esse tipo de espacialidade tem nos chamado a atenção os fenômenos de apropriação do espaço nos quais, grupos sociais se territorializam no/pelo espaço público, provocando a sua fragmentação. Este fato pode ser observado em parques, ruas, shoppings, praias, etc. É comum, por exemplo, observar no Parque Farroupilha de Porto Alegre durante o final de semana, grupos sociais distintos ocupando lugares também distintos nesse espaço público.

É importante destacar que os espaços públicos caracterizam-se em sua essência pela livre acessibilidade, ou seja, qualquer pessoa pode usufruir deste espaço sem restrição - logicamente, desde que obedeça a certos regramentos sociais. A grande questão é que ao se apropriarem deste espaço, os grupos sociais, que por Maffesoli (1998) tem sido chamados de tribos urbanas, redefinem o modo como se constitui o uso do espaço público. Como efeito deste processo, autores como Gomes (2002), apontam, inclusive, para um recuo da cidadania provocado pela fragmentação do espaço público.

Entretanto, será que este processo está restrito somente aos espaços tidos como públicos. A escola, que a nosso ver é um espaço coletivo, mas que não é um espaço público por excelência, na medida em que seu uso se restringe aos membros considerados da comunidade escolar (alunos, professores, funcionários, familiares dos alunos), também pode sofrer com este processo de fragmentação espacial provocado pela existência de tribos urbanas no seu interior. O pátio da escola é um exemplo de espaço comum, que, 
inclusive, possui certa conotação pública, na medida em que é o local de encontro entre os diferentes atores que compõem este lugar - ou seria Entre-Lugar? (CASTROGIOVANNI, 2005). Nestes espaços comuns ocorrerão processos de apropriação do espaço muito próximos daquilo que visualizamos nos espaços públicos de nossas cidades, afinal os alunos, até certo ponto, também se agrupam em tribos, de acordo com suas singularidades.

Dentro deste contexto, gostaríamos de salientar a complexidade necessária a compreensão das dinâmicas correspondentes ao espaço escolar, na medida em que ao mesmo tempo podemos considerar a escola como um todo, já que algumas características relativas às apropriações desse espaço ocorrem devido à sua singularidade (características próprias), assim como devemos entender a escola como parte de um todo maior que é a sociedade, do qual ela é integrante como produção e como produtora. Ou seja, existem questóes características do todo chamado escola que exigem, para o entendimento de sua dinâmica social, um pensamento que não se restrinja aos limites estabelecidos por suas cercas, pois a escola é parte de um todo maior que é o mundo. É o que Morin (2003) define como "princípio hologramático", onde as partes estão no todo e o todo está nas partes ${ }^{1}$.

Portanto neste ensaio procuraremos debater as relaçóes existentes entre o uso do espaço escolar e o uso do espaço público na sociedade contemporânea, através de uma abordagem que se propõe complexa, mas que certamente não atingirá toda a complexidade do tema, na medida em que o todo é intangível por estar em constante transformação. Além disso, procuramos ao final desse debate estabelecer a importância de se compreender os processos de apropriação do espaço para que possamos ter uma ação pedagógica mais condizente com a realidade social.

O todo é maior e menor do que a soma das partes, pois o todo possui características que a simples soma das partes não possui, assim como propriedades existentes nas partes são inibidas quando estabelecem a organização do todo (MORIN, 2008). 


\section{Território e territorialidades: formas de apropriação espacial}

Para começarmos nossa análise vale elucidar o arcabouço conceitual que dá suporte ao nosso texto. Sendo assim, chamamos a atenção para o que Milton Santos (2004, p.63) afirma com relação ao objeto da geografia, o espaço geográfico, que "[...] é um conjunto indissociável solidário e também contraditório, de sistemas de objetos e de sistemas de ações, não considerados isoladamente, mas como um quadro único no qual a história se dá”.

Milton Santos (2004), dessa forma, aponta que o espaço geográfico é uma totalidade em constante transformação. Além disso, o autor reforça a necessidade da análise social em compreender o uso que os indivíduos e a sociedade fazem do espaço, através do conceito de território usado. Essa noção de uso do espaço através do conceito de território usado é fundamental para a compreensão dos fenômenos de apropriação espacial que estamos abordando.

Outra aproximação ao nosso foco de debate tem como referência as palavras de Souza (1995) no que diz respeito ao conceito de território.

[...] o território é um campo de forças, uma teia ou uma rede de relações sociais que, a par de sua complexidade interna, define, ao mesmo tempo, um limite, uma alteridade, a diferença entre "nós" (o grupo, os membros da coletividade ou "comunidade", os insiders) e os outros (os de fora, os estranhos, os outsiders) (SOUZA, 1995, p. 80, grifo nosso).

O território como expressão de poder e de diferenciação dos grupos sociais pelo/no espaço, é de certa forma, o resultado de processos de apropriação espacial. Buscando aprofundar um pouco mais essa questão, temos que refletir sobre um derivado do conceito de território que é o conceito de territorialidade. As primeiras noções de territorialidade surgem junto a ciências naturais para retratar o comportamento animal com relação ao controle 
do espaço. Entretanto, torna-se arriscado fazer uma correlação direta entre a territorialidade animal e a territorialidade humana, na medida em que nossa sociedade está organizada sobre dimensões culturais, sociais, econômicas (HAESBAERT, 2004). Sobre a territorialidade humana, Sack (1986) afirma que essa é uma estratégia de domínio do espaço realizada por grupos ou indivíduos, através de uma relação de poder sobre uma determinada área.

Dentro deste contexto, a dialética entre identidade (entre os que estabelecem uma territorialidade) e alteridade (entre aqueles que não fazem parte do grupo territorializado), é novamente reforçada dentro da análise sócio-espacial, sendo, portanto, sempre uma relação.

Souza (1995, p. 99), nesse sentido, afirma que "[...] a territorialidade, no singular, remeteria a algo extremamente abstrato: aquilo que faz de qualquer território um território, isto é [...] relações de poder espacialmente delimitadas e operando sobre um substrato referencial”. Podemos concluir, portanto, que através das territorialidades os grupos sociais operam uma organização social contraditória que ao mesmo tempo fragmenta e reparte o espaço através de territórios - de diferentes escalas (macro, micro, nano, etc) - mas que ao produzir essa repartição (re) cria uma diversidade social inerente a vida cosmopolita que, inclusive, sob o signo da tolerância pode regenerar processos de compartilhamento do espaço. Contudo, sob o peso da intolerância, pode criar uma rigidez nos processos intercomunicacionais envolvendo diferentes grupos sociais.

Segundo Haesbaert e Gomes (2002) o espaço atua como fonte e condicionante para a constituição de determinados grupos sociais. Sendo a metrópole "[...] um território complexo onde se mesclam e se separam diversas identidades" (HAESBAERT; GOMES, 2002, p. 96), gerando um quadro de conflitos e de acordos territoriais entre diferentes grupos sociais. Essas territorialidades identitárias que se manifestam nas metrópoles também se expressarão no espaço escolar. 
Maffesoli (1998) é outra referência muito importante, pois traz a noção dos grupos como tribos. Para esse autor, existe um processo de neotribalismo operando dentro da sociedade atual, que busca romper com o individualismo proveniente da modernidade. Dentro deste contexto, se operam relações de "socialidade", que estão muito mais ligadas as dimensões culturais do que as dimensões políticas. O autor também salienta a importância do espaço na formação tribal. Num exemplo com relação a esta questão, ele afirma que ao analisar aglomerações populacionais percebe-se que elas:

[...] apresentam sutis diferenciações, e as preferências quanto às roupas, ou quanto aos hábitos sexuais, aos esportes, aos bandos, e aos próprios lugares não deixando de dividir o território, recriando, assim, um conjunto comunitário com funçôes diversificadas e complementares (MAFFESOLI, 1998, p. 140, grifo nosso).

Compreendidos, portanto, os conceitos que permitem entender os processos de apropriação espacial, devemos partir para a aplicação dessa ferramenta analítica em dois casos específicos: no espaço público e no espaço escolar.

\section{Espaços públicos e espaço escolar: diferenças e similaridades dos processos de apropriação espacial}

Como já dissemos anteriormente, os espaços públicos, como parques urbanos, tem sido alvo de processos de apropriação

\footnotetext{
2 A socialidade é quem constrói uma sociedade cada vez mais despreocupada com os assuntos políticos, e não o individualismo como alguns autores, tais como Sennett (1988), afirmam. Richard Sennett em seu livro, Declínio do Homem Público: As tiranias da intimidade (1988), fala que o narcisismo, advindo de uma sociedade individualista, pós-Antigo Regime, destrói o equilíbrio entre a vida pública e a vida privada, em detrimento da supervalorização da última. Sennett chega a falar em novo tribalismo, mas remete, ao contrário do que pensa Maffesoli, essa discussão a individualização da sociedade.
} 
espacial. Em Porto Alegre é comum vermos esse tipo de processo ocorrendo em parques como o Farroupilha, o Moinhos de Vento, o Marinha do Brasil, etc. Entretanto, cabe refletir o que caracteriza o espaço público enquanto um tipo de espacialidade. Desse modo, devemos afirmar que o espaço público é antes de tudo, conforme apontado por Gomes (2002, p. 162), “[...] qualquer tipo de espaço onde não haja obstáculos ao acesso e participação de qualquer tipo de pessoa".

Para Gomes (2002), o espaço público é aquele onde exercemos a cidadania, sendo a condição de livre acesso:

[...] respeitada e revivida, a despeito de todas as diferenças e discórdias entre os inúmeros segmentos sociais que aí circulam e convivem, ou seja, as regras de convívio e do debate devem ser absolutamente respeitadas [...] Por isso esse espaço é o lócus da lei. Poderíamos dizer que o espaço público é o lugar das indiferenças, ou seja, onde as afinidades sociais, os jogos de prestígio, as diferenças, quaisquer que sejam, devem se submeter às regras da civilidade (GOMES, 2002, p.162).

Contudo, a partir do momento em que temos apropriações do espaço público por determinados grupos, este sofre uma redução. Com isso, temos uma privação do público. GOMES (2002) afirmará que o resultado deste processo será um recuo da cidadania, pois o espaço que seria do encontro torna-se aquele da cisão.

Podemos encontrar parte da explicação sobre as apropriações no/do espaço público em Semprini (1999) que faz uma relação desse processo com o multiculturalismo contemporâneo. Cabe ressaltar que o espaço público se remete à política que nasce na diferença, mas que se projeta para a igualdade através de regramentos sociais. Semprini (1999) destaca que a emergência de uma sociedade muticultural reflete a decadência do espaço público, pois a supervalorização das diferenças culturais acaba por suprimir a política. Este novo espaço construído pela multiculturalidade é sócio-cultural. É um espaço que se complexifica nas relações sociais que nele surgem. 
Entretanto, ainda não temos a certeza de que este espaço público está em decadência com relação ao reforço das identidades culturais. Talvez o que haja é uma transformação deste espaço, com a acentuação de conflitos, e contraditoriamente, com uma maior abertura para mecanismos de diálogo. Mesmo que haja uma supervalorização dos aspectos culturais, não podemos dizer que isto se sobrepôs completamente a esfera política. No nosso entendimento, o próprio abandono da política pela ascensão das questóes culturais, pode reacender num sentido contrário a política como forma de diálogo entre os grupos³.

Com relação ao espaço escolar devemos dizer primeiramente que esse tipo de espacialidade não pode ser entendido, a nosso ver, como um espaço público, na medida em que restringe, no seu dia a dia, a entrada das pessoas que não fazem parte da comunidade escolar. Entretanto, por possuir espaços comuns, e por constituir-se como "um espaço de encontro", a escola possui aquilo que chamamos de pracialidade. Queiroga (2003 p. 139) traz o conceito de pracialidade para definir lugares que possuam conotação pública, servindo como espaço de encontro e de convivência social. $\mathrm{O}$ conceito de pracialidade tem relação com a praça, que na discussão sobre espaço público é sempre tida como principal exemplo. Entretanto a pracialidade não é exclusiva das praças. Existem locais chamados de praça que não possuem pracialidade, já que não promovem o encontro, sendo muitas vezes apenas um local de passagem.

Sobre a importância da praça como lugar de encontro e socialidade, trazemos essa breve observação feita por Maffessoli (1998, p. 140):

Se no entanto, como uma câmera invisível, ele souber levar em conta uma globalidade e, ao mesmo tempo, focalizar os detalhes, não poderá deixar de estar atento à potência arquitetônica que estrutura essas deambulações. [...] A Ágora antiga, ou mais próxima de nós a "passegiata" italiana, o passeio vespertino, no Sul da França, apresentam as mesmas características, e constituem lugares não negligenciáveis de socialidade.

Pfeiffer (2001) fala que o grande problema não está na esfera política, mas sim na esfera administrativa do Estado, que por vezes é confundida com a primeira. 
Portanto, afirmamos que a escola, embora não seja um espaço público por excelência, possui uma grande pracialidade, constituindo-se como "um lugar não negligenciável de socialidade". Agora ficam os seguintes questionamentos: $\mathrm{O}$ fato de a escola ser um lugar de encontro colabora para o surgimento de tribos em seu espaço? Isto explicaria alguns dos conflitos existentes no espaço escolar?

Primeiramente devemos destacar que como expressões de um espaço social, a escola e o espaço público tenderão a apresentar processos de apropriação sob a forma de territorialidades. Essas territorialidades existentes no espaço público e no espaço escolar são formas de consolidação desses grupos sociais (tribos). Se inscrever no espaço-tempo, demarcando uma territorialidade, significa reforçar a identidade do grupo como tal através de uma identidade territorial. Com a apropriação do espaço-tempo, os grupos se fortalecem como unidade que se diferencia das demais. Gomes (2002) reforça esta visão:

Este senso de exclusividade pode ser percebido nos propósitos das pessoas, na recusa a conviver sobre o mesmo espaço, estabelecendo horários estratégicos para evitar o encontro, ou ainda a adoção de acessórios e linguagem comportamental para estabelecer as diferenças (GOMES, p. 223)

Tal afirmação poderia destruir nosso debate na medida em que aponta a vontade que alguns grupos possuem de evitar o encontro. Contudo, se estamos defendendo que a escola é um espaço de encontro devido a sua conotação pública, é importante que se diga que assim como ocorre nos parques e nas praças de nossas cidades, nela ocorrerão - principalmente e preferencialmente - os encontros entre iguais, ou seja, daqueles indivíduos que fazem parte de uma mesma tribo. Dentro deste contexto, no espaço escolar, alguns conflitos podem emergir entre os diferentes atores, que representam diferentes papeis, nas diferentes tribos da escola. Mas talvez o maior conflito esteja na forma como o aluno usa o espaço escolar em contraposição ao que escola, enquanto instituição, projeta como uso ideal. Para os alunos a escola se 
torna importante como lócus de encontros sociais, entretanto seu papel institucional formador é, muitas vezes, desprestigiado. Ou seja, os alunos não vêem, primeiramente, a escola como um local de aprendizagem. A atração exercida pela escola está relacionada ao fato desse espaço se comportar como uma grande praça, que tem um apenas um grande problema: o fato de que para usá-la é necessário assistir aulas.

\section{A Escola como Praça: contradições internas e conflitos emergentes}

Para começarmos esta parte do texto é necessária a seguinte compreensão: "[...] a escola na atualidade é vista como um local de encontro". Como afirma Castrogiovanni (2005), a Escola é um entre-lugar na medida em que é um espaço para se turistificar. Isto porque, na visão de boa parte dos alunos, a escola não é o lugar para aprender, mas, por outro lado, é o lugar para se encontrar e se dividir (em tribos). Essa divisão é resultado da formação de territorialidades que a escola como espaço social propicia.

Acerca do debate com relação às territorialidades existentes no espaço escolar, Castrogiovanni (2005), ao detalhar o conceito de Entre-Lugar - por esse autor criado (adaptando o conceito de Terceiro Espaço de Bhabha) - diz que:

Este Terceiro Espaço parece ser um espaço temporal. Ele não existe na sua concretude material. Ele é representativo e depende de cada Sujeito, ao estabelecer relações entre o seu Lugar com o Lugar do outro, um outro Lugar. Ao mesmo tempo em que adquire uma espacialização e uma temporalização, pois depende, também, da relação do poder em um território, ele possibilita a existência de novos espaços, criando, novas territorialidades (CASTROGIOVANNI, 2005, p. 8, grifo nosso).

O Entre-Lugar, parece ser, uma espacialização multiterritorializada, que surge de comportamentos substanciados por sentimentos a partir da cultura e linguagem dos diferentes sujeitos (CASTROGIOVANNI, 2005, p. 11, grifo nosso). 
Reforçando a tese da escola como um entre-lugar podemos destacar algumas contradições. Por exemplo, o fato de estarmos aumentando os índices de escolaridade não significou necessariamente uma maior identificação com a instituição escola. Ou seja, a escola não é mais visualizada como locus da aprendizagem necessária para ascender socialmente. Este fato desprestigiou a escola como instituição, colaborando para a desvalorização dos profissionais que a compóem (professores). Afinal, aumentou-se o número de desempregados, contraditoriamente, no mesmo momento em que ocorreu um aumento na escolaridade da população brasileira. Esse processo possui relação com uma mudança estrutural no capitalismo (fordismo para toyotismo), que aumentou a reserva de desempregados. Desse modo, a escola passou a ser vista a partir do seguinte ditado: "Ruim com ela, pior sem ela”. Esta análise é reforçada por Spósito (2004, p. 78-79):

O mesmo processo de mutação social que constitui a "sociedade escolarizada", ou seja, a educação escolar como ferramenta essencial para a sobrevivência do indivíduo moderno no mundo (habilidades, conhecimentos e saberes, competências para uma melhor participação na esfera pública e afirmação de sua autonomia como sujeito), produz uma enorme crise de mobilidade social ascendente via escola, pela escassa capacidade de absorção no mundo do trabalho dessa população escolarizada. [...] A disseminação das oportunidades escolares transforma os diplomas em bens comuns $[\ldots]$.

Este mesmo processo que provocou a desvalorização da escola como instituição, levou ao aumento da criminalidade pela falta de perspectivas gerada com a ausência de empregos. A disseminação da criminalidade acarretou o abandono de alguns locais que antes serviam para o encontro, como parques e praças. A escola, dentro desse contexto, passa a ser, de certa forma, um local seguro para o encontro dos jovens. Os alunos, sem identificação com a instituição escola, passam a percebê-la apenas como um espaço de encontro.

A conotação pública que a escola ganhou faz com que ela se torne um local das mais diferentes exibições. A forma de se vestir e as posturas dentro de uma escola obedecem a lógica 
da visibilidade pública que este espaço oferece. Castrogiovanni $(2005$, p. 8$)$ fala que "[...] o Sujeito aluno, parece ser muitas vezes um turista que vai à escola para ver e poder ser visto".

Dentro deste contexto, algumas manifestações, como no caso das pichações, cada vez mais comuns no espaço escolar, têm o intuito de dar visibilidade a um determinado grupo - tal como acontece nos parques e praças da cidade. Ou seja, trata-se da manifestação do poder de um determinado grupo com relação a outro. Mas, também, torna-se uma forma de comunicação, na medida em que o poder para se consolidar e/ou se expandir necessita ser comunicado aos seus (pertencentes ao grupo) e aos outros (de grupos diferentes) ${ }^{4}$. Um grupo ganha expressividade quando agrega sua marca em locais de grande visibilidade, como a escola. Locais de grande visibilidade são desafiantes, porque esta condição exige cuidado na medida em que se pode ser vigiado pelo "inimigo".

Outro fato contraditório é que na escola (instituição) se constroem essas noções de civilidade necessárias para o convívio no espaço público. Ou seja, a escola é produtora dos sujeitos que vivem/constroem o espaço público. Porém algumas manifestações ocorrentes tanto nos espaços públicos quanto nas escolas, nos provam que a escola como instituição está em crise. Fica a pergunta: será possível superar esta crise a partir do modelo de escola existente?

\section{Ordem e desordem: desafios para a construção de uma nova escola}

Acreditamos ser difícil a superação desta crise a partir de um modelo de escola estruturalista e funcionalista. A escola se desprendeu da realidade, não servindo aos interesses atuais da sociedade. A forma como a escola constrói o conhecimento

Muitas vezes depredar de alguma forma a escola, serve como desafio para inserção de um Sujeito em algum grupo. Uma espécie de batismo. 
é extremamente reducionista, não preparando o jovem para a vida. Esta desconexão da escola com relação à vida é talvez um dos maiores problemas a serem enfrentados, já que isto colabora para o desinteresse dos jovens com relação a esta instituição. A escola divide o conhecimento/vida em disciplinas que separadas não formam um contexto, e que, portanto, não produzem vida/ conhecimento.

A ordem que é promovida pela escola atual está em xeque! Afinal, o desejo de uso do seu espaço, por parte dos alunos, não está relacionada com o seu papel de instituição de ensino. No contexto atual, a identificação que os alunos possuem com a escola tem relação, em grande parte, com a possibilidade de realização de encontros sociais ofertada nesse espaço. Segundo Castrogiovanni (2005), isto pode criar o Entre-Lugar, pois não há uma efetiva dialogicidade entre emissor e receptor. A dialogicidade é o cerne dos processos de ensino. A construção de um Entre-Lugar na escola parece construir a idéia da desordem. Agora, isto não significa o fim da ordem, afinal a desordem de agora pode ser a ordem de amanhã, dependendo da forma como se posiciona o Sujeito. Souza (1997) define, com relação ao tema:

[...] aquilo que é percebido como "ordem" por alguns pode bem ser percebido como "desordem" por outros, a desordem encarna simultaneamente, a angústia da dissolução de uma velha ordem e as incertezas que acompanham a formação de uma nova (SOUZA, 1997, p. 72).

Será que poderemos romper com este ciclo de ordem e desordem? No nosso entender, não. Ordem e desordem fazem parte de um movimento que não se cessa, pois a partir desses processos temos a construção de uma nova organização (MORIN, 2008). A grande questão envolvendo a escola está na sua desconexão com a realidade social na atualidade. Tal fato provoca uma desordem, que não deve ser entendida como o fim desta instituição, mas como o começo de outra ordem dentro deste mesmo espaço.

Segundo Spósito (2004, p. 87), é necessário para que consigamos construir uma nova escola: 
[...] aprofundar o conhecimento sobre as formas e os estilos de vida experimentados pelos jovens em suas várias práticas, para compreendêlos, e ao mesmo tempo, produzir novas referências que retomem em chave democrática a ação socializadora da escola, na especificidade de seus saberes e práticas".

Uma escola que sirva para construir incertezas, e não verdades, que teça o conhecimento contextualizando-o, que oriente para a reflexão da condição humana no mundo, que se atente para a compreensão mútua, e que conduza à "antropo-ética", segundo Morin (2002), "[...] compreende, assim, a esperança na completude da humanidade, como consciência e cidadania planetária". Cidadania e consciência para viver a vida nos diferentes espaços, sejam eles públicos ou não, sejam eles a praça ou a escola.

\section{Referências}

CASTROGIOVANNI, Antônio Carlos. A complexidade do espaço geográfico escola: Lugar para estudar ou Entre-Lugar para turistificar?. Porto Alegre, 2005.

GOMES, Paulo César da Costa. A Condição Urbana: Ensaios de Geopolítica da cidade. Rio de Janeiro: Bertrand Brasil, 2002.

HAESBAERT, Rogério; GOMES, Paulo César da Costa: O Espaço na Modernidade. In: HAESBAERT, Rogério. Territórios Alternativos. São Paulo: Contexto, p. 77-100, 2002.

HAESBAERT, Rogério. $O$ Mito da Desterritorialização: Do fim dos territórios à multerritorialidade. Rio de Janeiro: Bertrand Brasil, 2004.

MAFFESOLI, Michel. O Tempo da Tribos: O declínio do individualismo nas sociedades de massa. 2 ed., Rio de Janeiro: Forense Universitária, 1998.

MORIN, Edgar. Os Sete Saberes necessários à Educação do Futuro. 5 ed., São Paulo: Cortez; Brasília: UNESCO, 2002.

MORIN, Edgar. O Método 5: a humanidade da humanidade. 2 ed., Porto Alegre: Sulina, 2003. 
MORIN, Edgar. O Método 1. a natureza da natureza. 2 ed., Porto Alegre: Sulina, 2008.

PFEIFFER, Cláudia Castellanos. Cidade e sujeito escolarizado. In: ORLANDI, Eni de Lourdes Puccinelli (Org.). Cidade Atravessada: os sentidos públicos no espaço urbano. Campinas: Pontes, p. 29-33, 2001.

QUEIROGA, Eugênio Fernandes. O Lugar da Praça: Pracialidades Contemporâneas na Megalópole do Sudeste Brasileiro. In: SOUZA, Maria Adélia Aparecida. (Org.). Território Brasileiro: Usos e Abusos. Campinas: Territorial, p. 131-145, 2003.

SANTOS, Milton. A Natureza do Espaço: Técnica e Tempo. Razão e Emoção. 4 ed., São Paulo: Edusp, 2004.

SANTOS, Milton. O retorno do território. In: SANTOS, Milton; SILVEIRA, Maria Laura; SOUZA, Maria Amélia Aparecida de; Território: Globalização e Fragmentação. 4 ed., São Paulo: Hucitec/ ANPUR, p. 15-20, 1998.

SEMPRINI, Andrea. Multiculturalismo. Bauru: Edusc, 1999.

SENNETT, Richard. O Declínio do Homem Público. As tiranias da intimidade. São Paulo: Cia. das Letras,1988.

SOUZA, Marcelo José Lopes de. O território: sobre espaço poder e desenvolvimento. In: CASTRO, Iná Elias de; CORRÊA, Roberto Lobato; GOMES, Paulo César da Costa. Geografia: Conceitos e Temas. 2 ed., Rio de Janeiro: Bertrand Brasil, p. 77-116, 2000.

SOUZA, Marcelo José Lopes de. A expulsão do paraíso. O "paradigma da complexidade" e o desenvolvimento sócio-espacial. In: CASTRO, Iná Elias de; GOMES, Paulo César da Costa; CORREAA, Roberto Lobato (Org.). Explorações geográficas. Rio de Janeiro: Bertrand Brasil, p. 4387, 1997.

SPÓSITO, Marílio Pontes. (Des)encontros entre os jovens e a escola. In: FRIGOTTO, Gaudêncio; CIAVATTA, Maria (Orgs.). Ensino médio: ciência, cultura e trabalho. Brasília: MEC, SEMTEC, p. 73-91, 2004. 